\title{
Open Abdomen in a Critically Ill Patient
}

\author{
Lalita Gouri Mitra ${ }^{1}$, Vandana Saluja ${ }^{2}$, Udit Dhingra ${ }^{3}$
}

\begin{abstract}
One of the damage control strategies used to avoid or treat abdominal compartment syndrome is "open abdomen (OA)," where the facial edges and the skin is left open, exposing the abdominal viscera. Although it reduces the mortality both in trauma and non-trauma abdominal complications, it does create a significant challenge in an intensive care setting, as it has physiological consequences that need early recognition and prompt treatment both in the intensive care unit and in the operating room. The article aims to review literature on "open abdomen," describe the challenges in such cases, and proposes a guideline for the intensivist in managing a patient with an OA.

Keywords: Abdominal compartment syndrome, Enteroatmospheric fistula, Negative pressure wound therapy, Open abdomen, Peritoneal sepsis, Primary or temporary abdominal closure.

Indian Journal of Critical Care Medicine (2020): 10.5005/jp-journals-10071-23613
\end{abstract}

\section{INTRODUCTION}

Damage control surgery (DCS) techniques like open abdomen $(\mathrm{OA})$, where the facial edges and the skin are purposefully left open, thereby exposing the abdominal viscera, are used in $10-15 \%$ of trauma laparotomies ${ }^{1}$ Pancreatitis, abdominal trauma, massive or extensive burns, ruptured aortic aneurysm, sepsis, and retroperitoneal hemorrhage are some scenarios, where pressurerelated end-organ dysfunction occurs due to increase in the volume of the intra-abdominal content manifesting in the form of hemodynamic, renal, ventilatory, and central nervous system compromise. The general indications for $\mathrm{OA}$ are damage control $40 \%$, facilitate early second look $25 \%$, multiple reasons $20 \%$, excessive contamination $10 \%$, and decompression to prevent or treat abdominal compartment syndrome (ACS) 5\%., ${ }^{2,3}$

Although using OA strategy can reduce mortality, ${ }^{3}$ it creates multiple challenges for the intensivist, as these patients are highly catabolic, loose a lot of fluid and proteins, suffer from nutritional insufficiency, and hemodynamic instability. OA also creates a challenge for the surgeon due to the development of an enteroatmospheric fistula (EAF), where the gastrointestinal content leaks into the OA field that can be catastrophic. The other surgical issues are ileus (13\%), anastomotic leak (7\%), fascial dehiscence (11\%), and surgical site infection (19\%). ${ }^{4}$ Subsequently, the fascia retracts if it is not closed early and a ventral hernia develops. ${ }^{5}$

Ogilvie was the first to use this technique more than 80 years ago with the intent to allow the intra-abdominal infection to drain (principal of source control) to treat intra-abdominal sepsis. ${ }^{6}$ The first international consensus conference (ICC) on OA was held in Milan in December 2014 to develop evidence-based guidelines to correctly identify the indications for $O A$, to choose the right technique for temporary abdominal closure (TAC), treat enteric complications, and subsequently close the abdominal wall effectively. ${ }^{7}$ According to published guidelines of The Eastern Association for the Surgery of Trauma (EAST) practice management committee, level III evidence exists to support the use of the $\mathrm{OA}$ technique in trauma in the presence of acidosis $(\mathrm{pH}<7.2)$, hypothermia (temperature $<35^{\circ} \mathrm{C}$ ), and coagulopathy, where $>10$ units of red blood cells have been transfused or $>6 \mathrm{~L}$ of crystalloids have been administered in 24 hours. ${ }^{2,8,9}$

Björck modified his classification of OA in 2016 (Table 1). ${ }^{10}$ $\overline{{ }^{1-3} \text { Department of Anesthesia and Critical Care, Institute of Liver and }}$ Biliary Sciences, New Delhi, India

Corresponding Author: Lalita Gouri Mitra, Department of Anesthesia and Critical Care, Institute of Liver and Biliary Sciences, New Delhi, India, Phone: +91 9971792343, e-mail: Igmitra@hotmail.com

How to cite this article: Mitra LG, Saluja V, Dhingra U. Open Abdomen in a Critically III Patient. Indian J Crit Care Med 2020;24(Suppl 4): S193-S200.

Source of support: Nil

Conflict of interest: None

\section{Abdominal Compartment Syndrome}

Intra-abdominal pressure (IAP) is defined as the steadystate pressure present within the abdomen and is approximately $5-7 \mathrm{~mm} \mathrm{Hg}$ in adult ICU patients. Intra-abdominal hypertension (IAH) is defined as sustained and persistent pathological increase in IAP $>12 \mathrm{~mm}$ $\mathrm{Hg}$ and is graded from I to IV. When IAH is caused due to injury or disease in the abdominopelvic area, it is called primary IAH. IAH caused by conditions not originating in the abdominopelvic cavity is secondary to IAH. Abdominal compartment syndrome is defined as a sustained and persistent IAP $>20 \mathrm{~mm} \mathrm{Hg}$ [with or without an abdominal perfusion pressure (APP) $<60 \mathrm{~mm} \mathrm{Hg}$ ] associated with

\begin{tabular}{cll} 
Table 1: Björck amended classification of open abdomen $2016^{10}$ \\
\hline Grade & Description & \\
\hline I & A & $\begin{array}{l}\text { Clean OA without adherence between bowel } \\
\text { and abdominal cavity } \\
\end{array}$ \\
& B & Contaminated OA without adherence/fixity \\
II & A & Enteric leak, no fixation \\
& B & Clean OA developing adherence/fixity \\
& C Contaminated OA developing adherence/ \\
III & A & Eixity \\
& B & Cnteric leak, developing fixation \\
IV & & Contaminated, frozen abdomen \\
& & Established enteroatmospheric fistula, frozen \\
\end{tabular}

(0) The Author(s). 2020 Open Access This article is distributed under the terms of the Creative Commons Attribution 4.0 International License (https://creativecommons. org/licenses/by-nc/4.0/), which permits unrestricted use, distribution, and non-commercial reproduction in any medium, provided you give appropriate credit to the original author(s) and the source, provide a link to the Creative Commons license, and indicate if changes were made. The Creative Commons Public Domain Dedication waiver (http://creativecommons.org/publicdomain/zero/1.0/) applies to the data made available in this article, unless otherwise stated. 
new organ dysfunction. ${ }^{11}$ Level I evidence whether one should resuscitate using this as an end point is not clear. ${ }^{12}$

According to the ICC on OA, empiric use of OA in trauma patients is indicated in the case of DCS for bleeding injuries requiring packing and planned re-exploration within a day or two (Grade II, LoE II) and if there is extreme visceral or retroperitoneal swelling or elevated bladder pressure after surgery (Grade II, LoE II), as these are the risk factors for ACS. ${ }^{7} \mathrm{~A} \mathrm{pH}<7.2$, core temperature $<34^{\circ} \mathrm{C}$, estimated blood loss $>4 \mathrm{~L}$, blood transfusion $>10 \mathrm{U}$ of packed red blood cells, systolic blood pressure $<70 \mathrm{~mm} \mathrm{Hg}$, lactate levels $>5$ $\mathrm{mmol} / \mathrm{L}$, base deficit $>-6$ in patients older than 55 years or $>-15$ in patients younger than 55 years, and/or prothrombin time $>1.6$ are indications of a patient who is physiologically fatigued and likely to develop ACS. ${ }^{9,13}$ As these risk factors are also associated with increased mortality and morbidity, the surgeon should therefore perform an abridged procedure and leave the abdomen open. ${ }^{13}$

ACS develops in acute pancreatitis due to peripancreatic inflammation, visceral edema secondary to resuscitation, and ileus. Percutaneous drainage has less morbidity and mortality than decompressive laparotomy and should be performed only if there is persistent organ dysfunction and IAH, despite catheter drainage..$^{13,14}$ Although early relief in ACS reduces hospital length of stay and mortality, it is still controversial regarding which method to use.

\section{Initial Non-surgical Management of Abdominal Compartment Syndrome}

The WCACS recommends that a baseline IAP should be recorded if two or more risk factors for ACS are present. Daily serial monitoring of IAP should be done at least once in an 8-hour shift; however, the optimal frequency has not been recommended. ${ }^{15}$ The gold standard for IAP measurement has been the intravesical technique using a Foley manometer $U$ tube by instilling $25 \mathrm{~mL}$ of physiological saline in the bladder.

Hypertonic saline and colloids are preferred over isotonic fluids, and restrictive fluid strategies should be used for resuscitation to prevent the development of ACS. ${ }^{16}$ Nonsurgical techniques that should be initiated are use of nasogastric and/or rectal tubes to remove the intraluminal contents, administering agents or enema that increases gut motility, use of neuromuscular blocking agents in ventilated patients, reducing the enteral intake, and colonic decompression. All these techniques have only theoretical benefit in decreasing IAP.

Thoracic epidural after initial resuscitation has been evaluated in a blinded, nonrandomized, prospective study by Hakobyan in which they found that it significantly reduced the mean IAP (16.8 $\mathrm{mm} \mathrm{Hg}$ to $6.3 \mathrm{~mm} \mathrm{Hg}$ ), thereby increasing the APP without any hemodynamic compromise. ${ }^{17}$ Percutaneous catheter drainage of any space-occupying fluid collection or resuscitation induced ascites can potentially improve APP and organ dysfunction, thereby avoiding a laparotomy. If the decrease in IAP is $<9 \mathrm{~mm} \mathrm{Hg}$, and the amount of fluid drained is $<1 \mathrm{~L}$, it should be considered as a failure. If fulminant ACS develops with evidence of organ failure, laparotomy should be considered. ${ }^{11,18}$

\section{Effects of Intra-abdominal Hypertension and Clinical Manifestations of Abdominal Compartment Syndrome}

Rise in IAP impedes the venous return causing pressure changes that have the following multisystem effects and hemodynamic changes. ${ }^{14,19,20}$

\section{Respiratory System}

Raised diaphragm, poor compliance, and decreased functional residual capacity, and basal atelectasis, presenting as low-tidal volume, hypoxia, hypercarbia, and raised airway pressures.

\section{Gut and Liver}

Reduced splanchnic, hepatic, and portal flow presenting as edema, ischemia, and necrosis of the gut, metabolic acidosis, and higher incidence of hepatic artery thrombosis and portal vein thrombosis

\section{Renal System}

Decreased blood flow to the kidneys, renal venous congestion causing cortical arteriolar compression presenting as decreased urine output, rising creatinine, and renal failure.

\section{Circulatory System}

Compression of the inferior vena cava resulting in reduced preload and increased afterload presenting as hypotension, reduced cardiac output, and false elevation in central venous pressure (CVP) and wedge pressure.

\section{Central Nervous System}

Increased intrathoracic pressure with decreased cerebral venous outflow presenting as elevated intracranial pressure. are: $^{14}$

Important changes that occur at the time of open decompression

- Immediate improvement in lung compliance and tidal volume; hence, ventilatory parameters should be carefully monitored and readjusted.

- Increase in the cardiac output: if the patient is on inotropes, they should be titrated as per the recommended mean arterial pressure.

- A significant drop in central venous pressure may be observed; hence, resuscitate accordingly.

- Reduction in intracranial pressures by as much as $10 \mathrm{~mm} \mathrm{Hg}$ extremely important in patients of concomitant traumatic brain injury and position of the patient should be optimized accordingly.

\section{Intra-abdominal Sepsis}

The primary goal in the management of any infectious process is source control; hence, in the presence of intra-abdominal sepsis, infection should be drained, necrotic material debrided, and intestinal injury repaired by performing a laparotomy. Mortality among acidotic patients who are hemodynamically unstable with significant systemic involvement due to intra-abdominal sepsis can be reduced by application of OA. ${ }^{21}$

The proposed benefit of $O A$ is this subset of patients is that ACS can be prevented in those requiring high-volume resuscitation and repeated peritoneal toileting. It has been suggested that by removing cytokine-laden peritoneal fluid during peritoneal toileting, systemic inflammatory response can be reduced, and a prospective study analyzing the inflammatory component in the peritoneal fluid and serum of patients with temporary abdominal dressing after DCS is currently being conducted. ${ }^{22}$ Reexploration or a "second-look" operation may also be needed in patients with complex liver injury, duodeno-pancreatic injuries, and penetrating injuries caused by a blast or high-velocity weapons that lead to loss of the abdominal wall. 


\section{Ruptured Abdominal Aortic Aneurysm}

ACS develops in patients of ruptured AAA secondary to large volume resuscitation, reperfusion injury and formation of hematomas that are large space-occupying lesions causing pressure changes. Elective delayed fascial closure should be considered in patients who have the following risk factors for development of ACS as identified by Rasmussen: ${ }^{23}$

- Systolic blood pressure $<90 \mathrm{~mm} \mathrm{Hg}$ for $>18$ minutes (preoperative shock)

- Cardiac arrest (preoperatively)

- Hypothermia $<33^{\circ} \mathrm{C}$

- Severe metabolic acidosis base deficit $>13$

- Massive intraoperative resuscitation $>3.5 \mathrm{~L} /$ hour

- EAST guidelines recommend using DCS for patients who are at high risk for developing visceral edema or $\mathrm{IAH}^{8}$

\section{Management of Open Abdomen and its Definitive Closure}

A multidisciplinary approach with close interaction between the surgical and intensive care unit team is required to manage a critically ill patient with an OA which should be done in a specific staged process ${ }^{13,14}$ (Flowchart 1). This plan aims at reducing the risk of developing both primary and secondary ACS and ideally should begin right at the time of retrieval, followed through in the emergency room and ICU, till the operating room where the surgeon decides to keep an OA.

\section{ICU Management}

Prolonged OA delays extubation, predisposes to repeated infections, and increases the risk for enteroatmospheric fistulae, therefore optimizing the physiology for the early closure of the abdomen is the primary challenge for the intensivist. The "lethal triad" of hypothermia, acidosis, and coagulopathy ${ }^{24}$ that develops in patients of hemorrhage needs to be reversed by judicious resuscitation in the ICU.

\section{Hypothermia}

There is additional insensible heat loss with an OA in comparison to a closed abdomen although it has not been quantified. Even if one uses warm intravenous fluids, humidified warm gases, and heating blankets, approximately $4.6^{\circ} \mathrm{C}$ are lost per hour during laparotomy, and a drop in core temperature from $34^{\circ} \mathrm{C}$ to $<32^{\circ} \mathrm{C}$ has been associated with $40-100 \%$ increase in mortality in trauma patients. ${ }^{25,26}$ The harmful effects of hypothermia are:

- Cardiac dysrhythmias causing decreased cardiac output.

- Left shift of the oxygen dissociation curve hence poor oxygen delivery.

- Coagulopathy due to enzymatic dysregulation (raised prothrombin time and partial thromboplastin time) and platelet dysfunction (prolonged bleeding time).

Management/prevention of hypothermia:

- Continuous core temperature monitoring

- Administer fluids via fluid warmers and use warm saline for irrigation

- Warm and humidify ventilator circuits

- Remove wet linen and keep minimum surface area exposed

- Increase ambient room temperature

- Convection blankets and heating mattress

\section{Acidosis}

Hypotension, hypothermia, and ongoing hemorrhage cause hypoperfusion of tissue and development of acidosis. Severe acidosis $(\mathrm{pH}<7.1)$ further hampers tissue perfusion, worsening the hemodynamics, and coagulopathy. Look for compartment syndrome in an extremity or development of ACS, a missed injury or ongoing hemorrhage or occult sepsis, if lactate levels are increasing. 27

Flowchart 1: Staged approach for the treatment of open abdomen (adapted from Coccolini et al. ${ }^{14}$ )

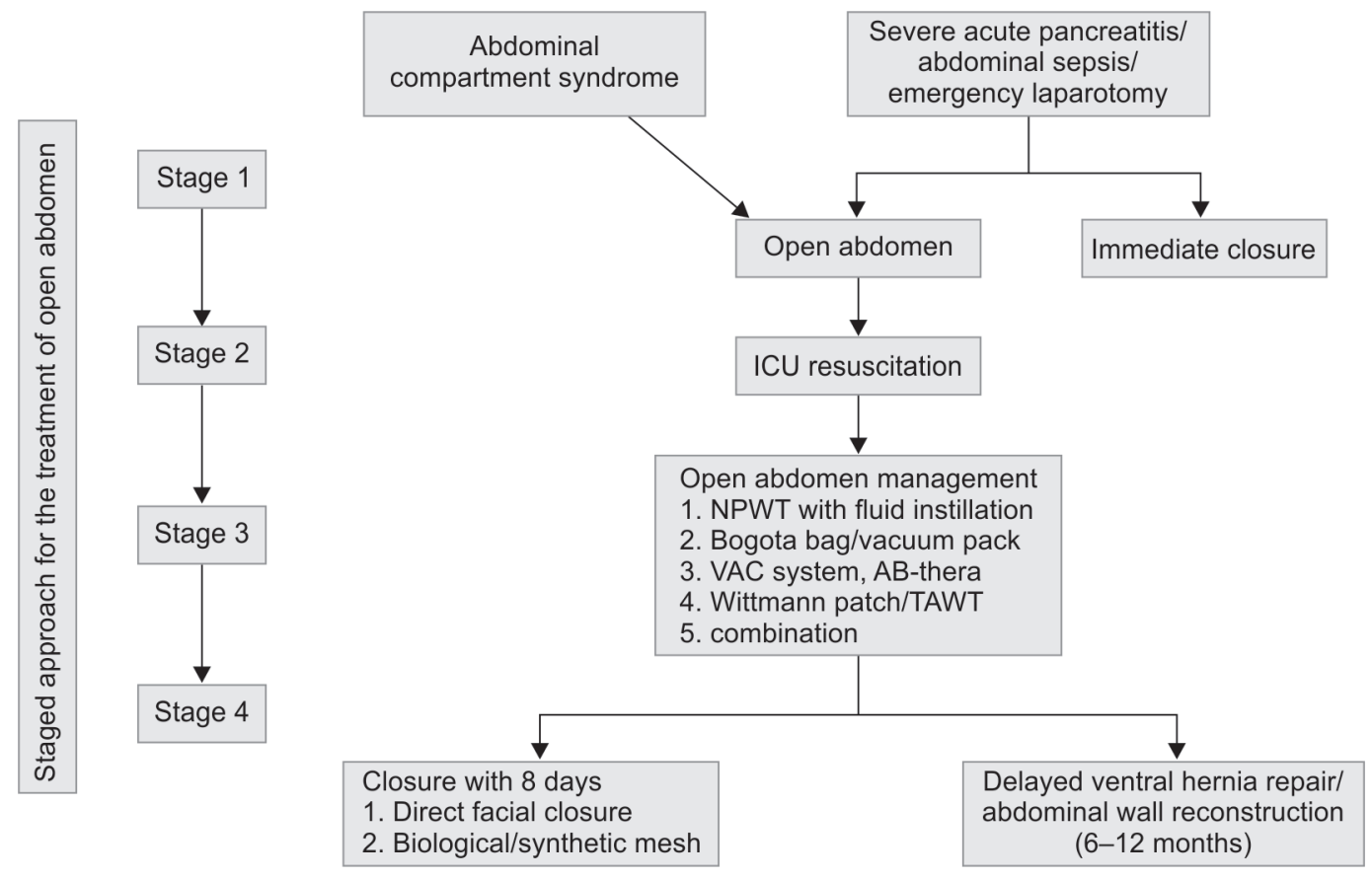


Management of acidosis:

- Monitoring of Arterial blood gases, electrolytes, and lactate clearance

- Avoid high-volume resuscitation to prevent increase in IAH which will further prolong $O A$

- Maintain hemodynamics

- Chase cultures and treat infection

\section{Coagulopathy}

Hypothermia, hypotension, acidosis, and ongoing hemorrhage requiring high-volume resuscitation in the form of intravenous fluids and blood products all-cause coagulopathy due to enzymatic dysregulation, hyperfibrinolysis, and platelet dysfunction.

Management of coagulopathy: ${ }^{28,29}$

- Increase core temperature to $37^{\circ} \mathrm{C}$ with 4 hours of arriving in the ICU

- Transfuse blood products to maintain PT $<15$, platelet count $>100,000$ and fibrinogen level $>100$, in the ratio of 2:1:1 or 1:1:1 as per the PROPPR trial (exact ratio can still be debated).

- Point of care tests for coagulation like thromboelastography and ROTEM has been recommended to guide product administration during DCS.

- Requirement of more than 2 units of RBCs per hour for 3 hours is an indication for angiography or re-exploration laparotomy.

\section{Ventilation}

Patients with ACS have decreased pulmonary compliance, and high ventilatory pressures may be required to mechanically ventilate these patients. However, since the transpulmonary pressure is elevated in ACS, the high ventilatory pressures do not over distend the alveoli. Hence, if the tidal volume is decreased to lower the airway pressures, it will cause hypoxia and respiratory acidosis. This can be fatal when a tense abdomen in ACS is opened.

Therefore, once the abdomen is decompressed, the ventilatory settings must be changed to maintain appropriate tidal volume to prevent overexpansion of the alveoli. Maintaining high minute ventilation initially and administering bicarbonate and calcium can prevent a cardiovascular collapse that can be precipitated by the sudden increase in the acid load from the abdomen. Sudden increase in venous return when the abdomen is decompressed can cause right ventricular overload if there is preexisting pulmonary hypertension due to hypercarbia or myocardial dysfunction due to sepsis, which can be treated with dobutamine or milrinone. A concomitant large pleural effusion that is compromising ventilation, may also need to be drained. ${ }^{27}$

Risk factors for the development of acute respiratory distress syndrome (ARDS) are $>10 \mathrm{~L}$ fluid resuscitation in first 24 hours, aspiration, pneumonia, sepsis, intestinal ischemia-reperfusion syndrome, acute pancreatitis, alcohol, and drugs. Pre-emptive lung-protective ventilation strategies should be applied in the presence of any risk factor. ${ }^{30}$

Patients with $O A$ are intubated and mechanically ventilated because of their underlying disease and there are several reports of patients of OA who have been extubated and made ambulatory with a low incidence of evisceration. The respiratory musculature usually compensates for the lack of negative subdiaphragmatic in the presence of an OA. A score of -2 to 0 on the Richmond AgitationSedation Scale/light sedation is usually sufficient when a temporary abdominal dressing is applied.

\section{Gut Edema and Fluid Balance}

Pathophysiology of gut edema in OA is multifactorial. During shock, the intravascular volume is preferentially shunted to the vital organs causing gut ischemia. Also, the mesenteric venous return is impaired when the IAP is elevated or the abdomen is packed, which causes congestion in an already ischemic gut. Post volume resuscitation, when an ischemic gut gets reperfused, there is free-radical mucosal damage and increased mucosal permeability leading to gut edema. ${ }^{30}$ Inhibition of the lymphatic outflow via the cisterna chyli due to raised CVP has also been implicated in the formation of gut edema.

Hence, the primary goal in the ICU is to minimize volume overload and prevent gut edema by balanced resuscitative measures so that a primary fascial closure (i.e., fascia-to-fascia closure of the abdominal wall within the index hospitalization) is possible after laparotomy as fluid-related weight gain of $>10 \%$ is a major risk factor for failure of primary closure.

Static indices like CVP and pulmonary artery occlusion pressure (PAOP) used to measure the intravascular volume may not be reliable in the presence of ACS or OA. Cheatham et al. in a study found right ventricular end-diastolic volume index (RVEDVI) to be a more accurate predictor of intravascular volume but could not give an optimal figure to target during resuscitation and recommended using markers like lactate to assess end-organ perfusion. ${ }^{31} \mathrm{Ghneim}$ et al. recommend using continuous stroke volume variation (SVV) as an end point, as it helps the intensivist to strictly titrate resuscitation to avoid hypoperfusion and volume overload, as it improved the time to primary fascial closure by 1 day. ${ }^{32}$

About 3\% saline which is hypertonic causes shift of the fluid to the intravascular space and potentially can attenuate the inflammatory response; hence, in a small observational study higher rate of primary fascial closure was possible, but it was not statistically significant. ${ }^{33}$ There is no randomized control trial about the use of albumin in OA, but since there is significant protein loss, there could be potential therapeutic benefit by using albumin as a resuscitative fluid.

\section{Nutrition}

The only major contraindication to enteral feeding is intestinal discontinuity. It has been well refuted in the literature that exposing the viscera does not cause paralytic ileus and feeding in OA does not cause gut edema; hence, early full enteral feeding should be initiated when feasible to maintain gut integrity, modulate the systemic inflammatory response, decrease the rate of infection, decrease the rate of ventilator-associated pneumonia, achieve early primary abdominal closure and decrease the rate of fistulas. ${ }^{34}$

It is estimated that $2-4.6 \mathrm{~g}$ of nitrogen is lost per liter of abdominal fluid output. Nitrogen balance and caloric need should be carefully calculated, and adequate amount of fluid, electrolyte, and proteins should be replaced according to the amount of fluid lost through the abdominal wound, as this is a major cause for underfeeding. Significant amount of potassium, phosphorus, magnesium, and calcium is also lost into the peritoneal fluid and hence should be adequately replaced..$^{35}$

There are no guidelines regarding which site to feed (stomach vs jejunum), amount of enteral nutrition (trophic vs goal tube feeds), or the use of specialized formulas. Animal studies have shown that a high-fat enteral diet may decrease intestinal mucosal barrier when the peritoneal is exposed to air. 

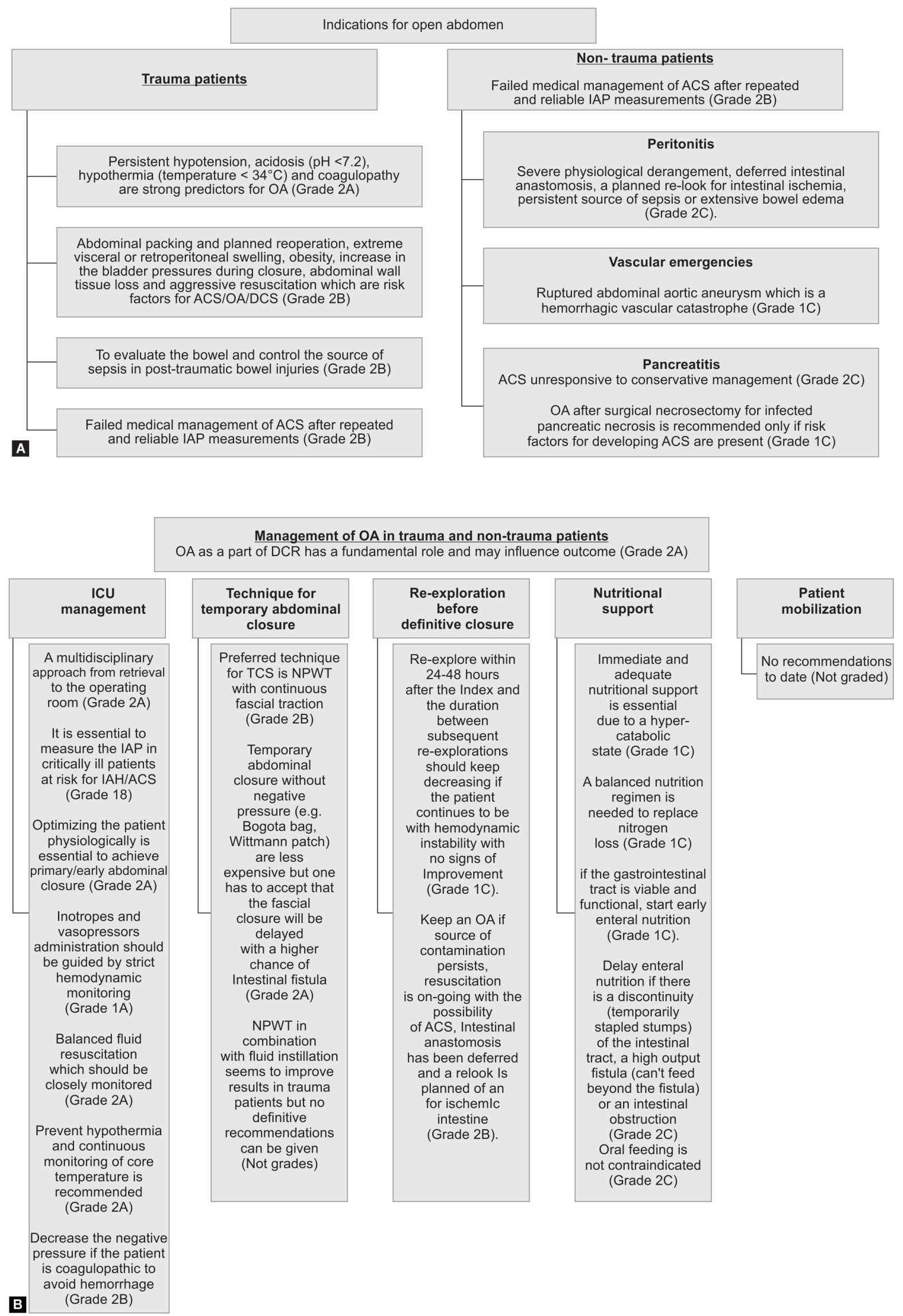

Figs 1 A and B: (A) Indications for OA (summary statements WSES 2016) Coccolini F et al. ${ }^{9}$ (B) Management (summary statements WSES 2016) Coccolini $\mathrm{F}$ et al. ${ }^{9}$ 

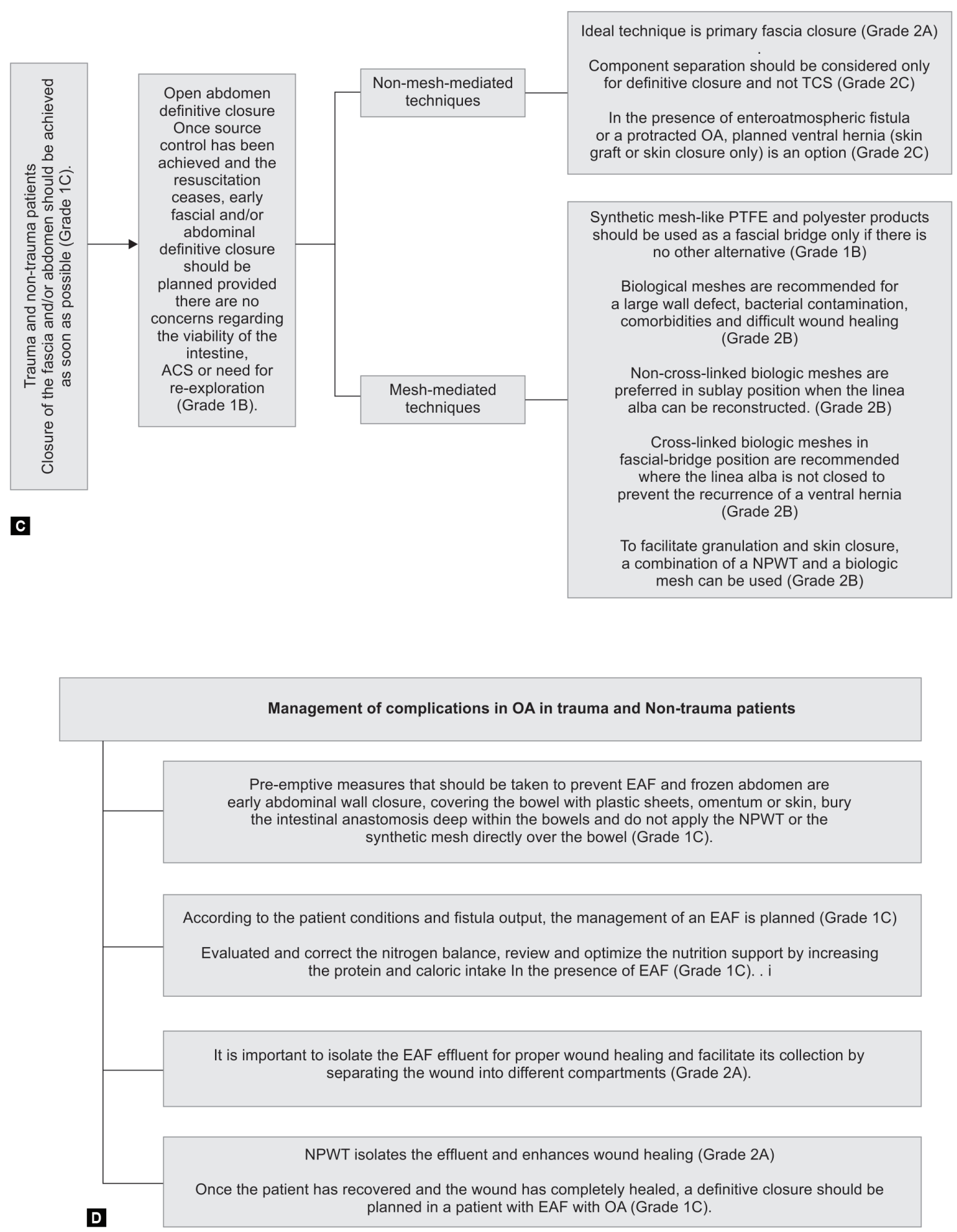

Figs 1C and D: (C) Definitive closure (summary statements WSES 2016) Coccolini F et al..$^{9}$ (D) Management of complications (summary statements WSES 2016) Coccolini F et al. ${ }^{9}$

\section{Infection and Sepsis}

Chances of an infectious complication increase after 8 days of $O A$. In all, $25 \%$ of patients with OA develop infectious complications in the form of wound infection, a deep abdominal abscess, or an intestinal fistula, which delays primary closure after an OA. The incidence of bloodstream infections is higher in such patients. Poor outcome is seen in almost $78 \%$ of the patients who develop gram-positive cocci and gram-negative bacilli intra-abdominal colonization. Antibiotics should be as per the disease process and cultures. There is limited role of prophylactic antibiotics, and a lot of emphases have been put to prevent catheter-associated bloodstream infections and VAP. Hence, whenever the patients are physiologically optimized, a primary fascial closure should be attempted. 


\section{Re-exploration}

The first relook should be attempted within 24 hours and no later than 48 hours after the initial laparotomy. Any patient requiring more than 2 units of RBCs per hour for 3 hours should be posted for a re-exploration. Progressive closure should be attempted with each reoperation if definitive abdominal closure cannot be done. ${ }^{36}$

\section{Surgical Management of Abdominal Compartment Syndrome/Open Abdomen}

\section{Temporary Abdominal Closure Techniques}

The ideal technique should be easy to apply and remove so that the surgeon can rapidly access the surgical site, should drain secretions, make nursing care, and the primary closure easier, and be easily available and affordable.

Currently, the following are available-Bogota Bag, Wittmann Patch, Vacuum pack with an adjustable pump to set the negative pressure, AB-Thera, ABRA system. ${ }^{9}$

\section{Definitive Closure}

Definitive closure should be done by applying split-thickness skin graft with a synthetic mesh. Alternatively, a Biological prosthesis (collagen mesh) can be used which allows blood, growth, and antiinflammatory factors to reach the surgical field. The non-crossed link meshes have a better tissue integration and local inflammatory reaction but have a faster re-absorption process. ${ }^{9}$

\section{Conclusion}

Abdominal compartment syndrome is the most common reason for leaving the abdomen open by reopening a laparotomy, not closing, or creating a fresh laparotomy. Routine monitoring of bladder pressures in high-risk patients should be a standard intensive care unit (ICU) protocol. The care of severely injured patients has improved with the application of OA. Surgery can be abridged in a physiologically depleted patient by doing a DCS as a part of DCM. OA can be managed by several TAC techniques; however, it is also associated with serious complications, such as severe fluid and protein loss, nutritional problems, EAFs, and development of massive incisional hernias. The most effective way to prevent or reduce these complications is to close the abdominal wall as soon as possible. Negative-pressure wound therapy may be associated with better outcomes than other temporary abdominal closure techniques. Definitive closure should be done only after the patients have recovered, depending on the duration of OA treatment and the size of the residual defect. The $\mathrm{OA}$ is associated with many early and late complications, including infections, gastrointestinal fistulas, and ventral hernias. Clinicians should be vigilant regarding the development of these complications.

Summary of statements from the World Society of Emergency Surgery guidelines (Fig. 1) ${ }^{9}$

\section{Author Contribution}

- Written the main script and complied the literature.

- Drafting the work or revising it critically for important intellectual content.

- Drafting the work or revising it critically for important intellectual content.

\section{ACKnOWLedgment}

Special thanks to Dr Federico Coccolini (General Emergency and Trauma Surgery, Bufalini Hospital, Viale Giovanni Ghirotti, 286, 47521 Cesena, Italy) for his valuable suggestions and permission to adapt his figures.

\section{References}

1. Demetriades $D$, Salim A. Management of the open abdomen. Surg Cin North Am 2014;94(1):131-153. DOI: 10.1016/j.suc.2013.10.010.

2. Sugrue M. Abdominal compartment syndrome and the open abdomen; any unresolved issues? CurrOpinCrit Care 2017;23(1):73-78. DOI: $10.1097 / \mathrm{mcc} .0000000000000371$.

3. Coccolini F, Montori G, Ceresoli M, Catena F, Moore EE, Ivatury R, et al. The role of open abdomen in non-trauma patient: WSES consensus paper. World J Emerg Surg 2017;12(1):39-56. DOI: 10.1186/s13017-0170146-1.

4. Harvin JA, Wray CJ, Steward J, Lawless RA, McNutt MK, Love JD, et al. Control the damage: morbidity and mortality after emergent trauma laparotomy. Am J Surg 2016;212(1):34-39. DOI: 10.1016/j. amjsurg.2015.10.014.

5. Campbell A, Chang M, Fabian T, Franz M, Kaplan M, Moore $F$, et al. Management of the open abdomen: From initial operation to definitive closure. Am Surg 2009;75(1):S1-S22. DOI: $10.1177 / 000313480907500101$.

6. Kreis BE, de Mol van Otterloo AJ, Kreis RW. Open abdominal management: a review of its history and a proposed management algorithm. Med Sci Monit 2013;19:524-533. DOI: 10.12659/ msm.883966.

7. Chiara O, Cimbanassi S, Biff W, Leppaniemi A, Henry S, Scalea TM, et al. International consensus conference on open abdomen in trauma. J Trauma Acute Care Surg 2016;80(1):173-183. DOI: 10.1097/ TA.0000000000000882.

8. Diaz JJ, Cullinane DC, Dutton WD, Jerome R, Bagdonas R, Bilaniuk $\mathrm{JO}$, et al. The management of the open abdomen in trauma and emergency general surgery: part 1-damage control. J Trauma 2010;68(6):1425-1438. DOI: 10.1097/TA.0b013e3181da0da5.

9. Coccolini F, Roberts D, Ansaloni L, Ivatury R, Gamberini E, Kluger Y, et al. The open abdomen in trauma and non-trauma patients: WSES guidelines. World J Emerg Surg 2018;13(1):7-22. DOI: 10.1186/s13017018-0167-4.

10. Björck M, Kirkpatrick AW, Cheatham M, Kaplan M, Leppäniemi A, de Waele JJ. Amended classification of the open abdomen. Scand J Surg 2016;105(1):5-10. DOI: 10.1177/1457496916631853.

11. Kirkpatrick AW, Roberts DJ, De Waele J, Jaeschke R, Malbrain MLNG De Keulenaer B, et al. Intra-abdominal hypertension and the abdominal compartment syndrome: update consensus definitions and practical guidelines from the World Society of Abdominal Compartment syndrome. Intensive Care Med 2013;39(7):1190-1206. DOI: 10.1007/s00134-013-2906-z.

12. Cheatham ML, White MW, Sagraves SG, Johnson JL, Block EF. Abdominal perfusion pressure: a superior parameter in the assessment of intra-abdominal hypertension. J Trauma 2000;49(4):621-627. DOI: 10.1097/00005373-200010000-00008.

13. Cipolla J, Stawicki SP, Hoff WS, McQuay N, Hoey BA, Wainwright G, et al. A proposed algorithm for managing the open abdomen. Am Surg 2005;71(3):202-207. DOI: 10.1007/s00384-010-0887-8.

14. Coccolini F, Biffl W, Catena F, Ceresoli M, Chiara O, Cimbanassi S, et al. The open abdomen, indications, management and definitive closure. World J EmergSurg 2015;10(1):32. DOI: 10.1186/s13017-015-0026-5.

15. Radenkovic DV, Johnson CD, Milic N, Gregoric P, Ivancevic N, Bezmarevic $M$, et al. Interventional treatment of abdominal compartment syndrome during severe acute pancreatitis: current status and historical perspective. Gastroenterol Res Pract 2016;2016:1-6. DOI: 10.1155/2016/5251806.

16. Cheatham ML, Malbrain MLNG, Kirkpatrick A, Sugrue M, Parr M, De Waele J, et al. Results from the international conference of experts 
on intra-abdominal hypertension and abdominal compartment syndrome. Il. recommendations. Intensive Care Med 2007;33(6):951962. DOI: 10.1007/s00134-007-0592-4.

17. Oda J, Ueyama $M$, Yamashita $K$, Inoue $T$, Noborio $M$, Ode $Y$, et al. Hypertonic lactated saline resuscitation reduces the risk of abdominal compartment syndrome in severely burned patients. J Trauma 2006;60(1):64-71. DOI: 10.1097/01.ta.0000199431.66938.99.

18. Hakobyan RV, Mkhoyan GG. Epidural analgesia decreases intraabdominal pressure in postoperative patients with primary intra-abdominal hypertension. Acta Clin Belg 2008;63(2):86-92. DOI: 10.1179/acb.2008.63.2.005

19. Cheatham ML, Safcsak K. Percutaneous catheter decompression in the treatment of elevated intraabdominal pressure. Chest 2011;140(6):1428-1435. DOI: 10.1378/chest.10-2789.

20. Ertel W, Oberholzer A, Platz A, Stocker R, Trentz O. Incidence and clinical pattern of the abdominal compartment syndrome after "damage-control" laparotomy in 311 patients with severe abdominal and/or pelvic trauma. Crit Care Med 2000;28(6):1747-1753. DOI: 10.1097/00003246-200006000-00008.

21. Sartelli M, Abu-Zidan FM, Ansaloni L, Bala M, Beltrán MA, Biffl $W L$, et al. The role of the open abdomen procedure in managing severe abdominal sepsis: WSES position paper. World J EmergSurg 2015;10(1):35. DOI: 10.1186/s13017-015-0032-7.

22. Roberts DJ, Jenne CN, Ball CG, Tiruta C, Léger C, Xiao Z, et al. Efficacy and safety of active negative pressure peritoneal therapy for reducing the systemic inflammatory response after damage control laparotomy (the intra-peritoneal vacuum trial): study protocol for a randomized controlled trial. Trials 2013;14(1):141. DOI: 10.1186/17456215-14-141.

23. Rasmussen TE, Hallett JW, Noel AA, Jenkins G, Bower TC, Cherry KJ, et al. Early abdominal closure with mesh reduces multiple organ failure after ruptured abdominal aortic aneurysm repair: guidelines from a 10-year case-control study. J Vasc Surg 2002;35(2):246-253. DOI: 10.1067/mva.2002.120384.

24. Kashuk JL, Moore EE, Millikan JS, Moore JB. Major abdominal vascular trauma-a unified approach. J Trauma 1982;22(8):672-679. DOI: 10.1097/00005373-198208000-00004.

25. Burch JM, Denton JR, Noble RD. Physiologic rationale for abbreviated laparotomy. Surg Clin North Am 1997;77(4):779-782. DOI: 10.1016/ s0039-6109(05)70583-1.
26. Jurkovich GJ, Greiser WB, Luterman A, Curreri PW. Hypothermia in trauma victims: an ominous predictor of survival. J Trauma 1987;27(9):1019-1024. DOI: 10.1097/00005373-19870900000011.

27. Chabot E, Nirula R. Open abdómen critical care management principles: resuscitation, fluid balance, nutrition, and ventilator management. Trauma Surg Acute Care Open 2017;2(1):1-9. DOI: 10.1136/tsaco-2016-000063.

28. Sagraves SG, Toschlog EA, Rotondo MF. Damage control surgery-the intensivist's role. J Intensive Care Med 2006;21(1):5-16. DOI: $10.1177 / 0885066605282790$.

29. Da Luz LT, Nascimento B, Shankarakutty AK, Rizoli S, Adhikari NK. Effect of thromboelastography (TEG) and rotational thromboelastometry $\left(\mathrm{ROTEM}^{\circledR}\right)$ on diagnosis of coagulopathy, transfusion guidance and mortality in trauma: descriptive systematic review. Crit Care 2014;18(5):518. DOI: 10.1186/s13054-014-0518-9.

30. Griggs C, Butler K. Damage control and the open abdomen: challenges for the nonsurgical intensivist. J Intensive Care Med 2016;31(9):567-576. DOI: 10.1177/0885066615594352.

31. Cheatham ML, Safcsak K, Block EF, Nelson LD. Preload assessment in patients with an open abdomen. J Trauma 1999;46(1):16-22. DOI: 10.1097/00005373-199901000-00004.

32. Ghneim MH, Regner JL, Jupiter DC, Kang F, Bonner GL, Bready MS, et al. Goal directed fluid resuscitation decreases time for lactate clearance and facilitates early fascial closure in damage control surgery. Am J Surg 2013;206(6):995-1000. DOI: 10.1016/j.amjsurg.2013. 07.021.

33. Harvin JA, Mims MM, Duchesne JC, Cox CS, Wade CE, Holcomb JB, et al. Chasing 100\%: The use of hypertonic saline to improve early, primary fascial closure after damage control laparotomy. J Trauma Acute Care Surg 2013;74(2):426-430. DOI: 10.1097/TA.0b013e31827e2a96.

34. Moore SM, Burlew CC. Nutrition support in the open abdomen. Nutr Clin Pract 2016;31(1):9-13. DOI: 10.1177/0884533615620420.

35. Wade C, Wolf SE, Salinas R, Jones JA, Rivera R, et al. Loss of protein, immunoglobulins, and electrolytes in exudates from negative pressure wound therapy. Nutr Clin Pract 2010;25(5):510-516. DOI: 10.1177/0884533610379852.

36. Demetriades $D$. Total management of the open abdomen. Int Wound J 2012;9(Suppl 1):17-24. DOI: 10.1111/j.1742-481X.2012. 01018.x. 